06;09

\title{
Люминесцентные плазмонные структуры из наночастиц золота и углеродных наноточек в мезопористых частицах кремнезема
}

\author{
(ㄱ Д.А. Курдюков, Д.А. Еуров \\ Физико-технический институт им. А.Ф. Иоффре РАН, Санкт-Петербург, Россия \\ ฯ E-mail: edan@mail.ru
}

Поступило в Редакцию 29 мая 2020 г.

В окончательной редакции 29 мая 2020г.

Принято к публикации 18 июня 2020г.

\begin{abstract}
Синтезированы композитные плазмонные структуры, состоящие из наночастиц золота и углеродных наноточек в монодисперсных сферических мезопористых частицах кремнезема. Продемонстрировано трехкратное усиление интенсивности видимой фотолюминесценции углеродных наноточек в данных структурах по сравнению с таковой для структур, не содержащих золотых наночастиц.
\end{abstract}

Ключевые слова: плазмонные структуры, наночастицы золота, углеродные наноточки, мезопористый кремнезем, люминесценция.

DOI: 10.21883/PJTF.2020.18.50002.18402

Углеродные наноточки (C-dots, CD) благодаря технологичным и недорогим методам синтеза, уникальным физическим и химическим свойствам, а также перспективам применения активно изучаются в последнее десятилетие [1-3]. По сравнению с полупроводниковыми квантовыми точками CD обладают рядом преимуществ, a именно биосовместимостью, низкой токсичностью, растворимостью в воде, химической инертностью, фотостабильностью [1-3]. Наибольший интерес проявляется к исследованиям люминесцентных свойств, так как они являются основой для целого ряда приложений CD в биологии и медицине [1-3], например в качестве маркеров и биосенсоров.

Увеличение интенсивности фотолюминесценции (ФЛ) углеродных наноточек, необходимое для оптических и биомедицинских приложений, может быть достигнуто благодаря взаимодействию с располагаемыми на определенном расстоянии от них металлическими плазмонными наноструктурами [4]. В частности, авторы работы [5] показали, что раствор $\mathrm{CD}$, нанесенный на подложку с наночастицами серебра (AgNP), демонстрирует увеличение от 1.5 до 10 раз интенсивности ФЛ (в зависимости от условий возбуждения) и бо́льшую фотостабильность по сравнению с таким же раствором на стеклянной подложке без металлических наночастиц. Еще один подход к получению пространственно разделенных CD и AgNP был реализован посредством добавления их в реакционную смесь при синтезе сферических частиц мезопористого кремнезема $\left(\mathrm{SiO}_{2}\right)$. Интенсивность ФЛ $\mathrm{CD}$ в составе композитных частиц увеличилась приблизительно в 3 раза по сравнению с интенсивностью ФЛ CD в растворе [6].

Отметим, что частицы $m \mathrm{SiO}_{2}$ вследствие высокой адсорбционной емкости, возможности модификации, биосовместимости и благодаря другим функциональным свойствам являются перспективной платформой для биомедицинских приложений [7,8]. Так, например, на их основе созданы многофункциональные гибридные частицы со структурой типа композитное ядро $\left(m \mathrm{SiO}_{2} / \mathrm{Gd}_{2} \mathrm{O}_{3}: \mathrm{Eu}^{3+}\right)$-оболочка мезопористого кремнезема, способные выполнять одновременно терапевтические (нейтрон-захватная терапия и адресная доставка лекарств) и диагностические (контрастное средство для магнитно-резонансной томографии и люминесцентный маркер) функции [9]. Металлические наночастицы и углеродные наноточки в составе многофункциональных частиц на основе $m \mathrm{SiO}_{2}$ зачастую играют определяющую роль для применения в биомедицине $[10,11]$. Так, частицы $m \mathrm{SiO}_{2}$, содержащие в порах наночастицы золота (AuNP), были недавно успешно применены для комбинированной иммунотерапии и фототермической терапии рака [10]. С помощью люминесцентных гибридных частиц, состоящих из ядра $\mathrm{mSiO}_{2}$, покрытого АТФ-аптамером, сопряженным посредством $\pi$-связей с графеновыми CD, был реализован мониторинг контролируемого аптамером выхода из пор $\mathrm{mSiO}_{2}$ противоракового химиопрепарата (доксорубицина) внутри клеток HeLa [11].

В настоящей работе темплатным методом получены композитные структуры, состоящие из монодисперсных частиц $m \mathrm{SiO}_{2}$, содержащих наночастицы золота и углеродные наноточки, обладающие яркой фотолюминесценцией в видимой области спектра, которая усилена благодаря взаимодействию с наночастицами золота.

Используемые в качестве темплата для синтеза композитных структур частицы $m \mathrm{SiO}_{2}$ получены гидролизом тетраэтоксисилана в спирто-водно-аммиачной среде, содержащей поверхностно-активный структурообразующий агент [12]. Внутри частиц имелась система плотноупакованных монодисперсных цилиндрических пор диаметром $3.1 \pm 0.2 \mathrm{~nm}$. Объемная доля пор составила 


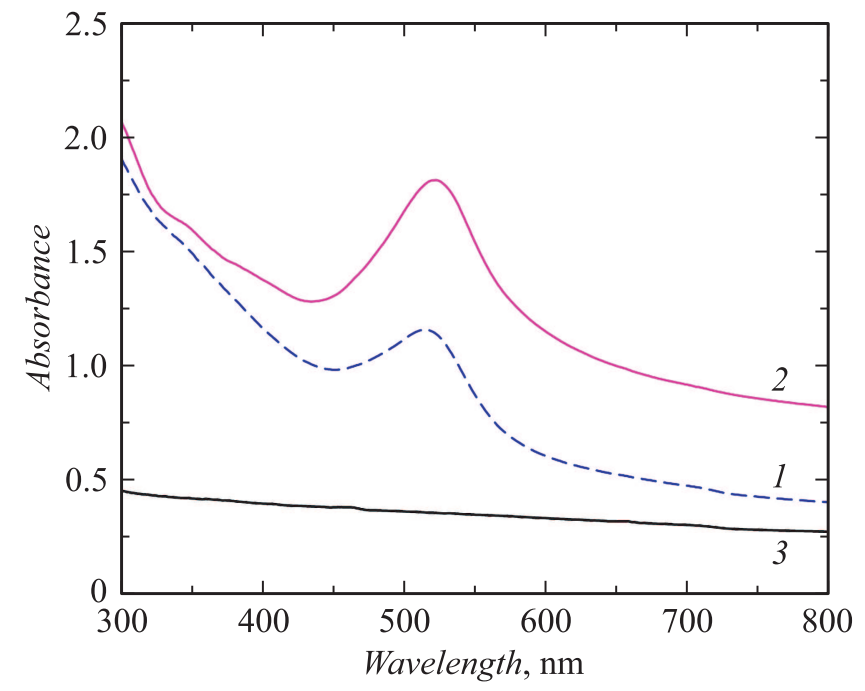

Pис. 1. Спектры поглощения частиц $m \mathrm{SiO}_{2} / \mathrm{CD}$ (1), $m \mathrm{SiO}_{2} / \mathrm{Au} / \mathrm{CD}(2), \mathrm{SSiO}_{2}$ (3).

50 vol.\% от объема частиц. Диаметр частиц $m \mathrm{SiO}_{2}$ был равен $450 \pm 20 \mathrm{~nm}$.

Получение наночастиц золота в $m \mathrm{SiO}_{2}$ осуществлялось в два этапа. На первом этапе проводилось введение водного раствора $\mathrm{HAuCl}_{4}$ в поры темплата под действием капиллярных сил с последующей сушкой при обычных условиях. На втором этапе частицы $\mathrm{mSiO}_{2}$, содержащие в порах прекурсор, отжигались в потоке водорода при $200^{\circ} \mathrm{C}$ до полного перехода хлоридов золота в Аu. Объемная доля элементарного золота в композитных частицах $m \mathrm{SiO}_{2} / \mathrm{Au}$ составила $\sim 2$ vol.\%.

Синтез углеродных наноточек в порах частиц $m \mathrm{SiO}_{2}$ и $m \mathrm{SiO}_{2} / \mathrm{Au}$ проводился посредством термического разложения углеродсодержащего прекурсора $[13,14]$. Частицы пропитывались спиртовым раствором Родамина 6Ж $(\mathrm{R} 6 \mathrm{G})$ с последующей термообработкой на воздухе при температуре $280^{\circ} \mathrm{C}$. Содержание углеродных наноточек в композитных частицах $m \mathrm{SiO}_{2} / \mathrm{CD}$ и $m \mathrm{SiO}_{2} / \mathrm{Au} / \mathrm{CD}$ было одинаковым и составило $\sim 2$ vol.\%. По данным адсорбционного структурного анализа рассчитаны удельная поверхность и объем пор в частицах $m \mathrm{SiO}_{2} / \mathrm{Au} / \mathrm{CD}$, которые составили $420 \mathrm{~m}^{2} / \mathrm{g}$ и $0.3 \mathrm{~cm}^{3} / \mathrm{g}$ соответственно.

Спектры поглощения полученных композитных структур в диапазоне $300-800 \mathrm{~nm}$ (рис. 1) измерялись на спектрофотометре с интегрирующей сферой Shimadzu UV 3600 Plus. Суспензии с одинаковой объемной концентрацией частиц 0.05 vol.\% помещались в кварцевые кюветы. Спектры ФЛ (рис. 2) данных суспензий изме-

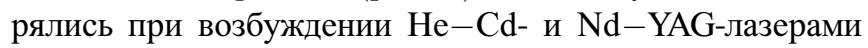
с длинами волн 325 и $532 \mathrm{~nm}$ соответственно при комнатной температуре и регистрировались с помощью управляемого компьютером монохроматора МДР-23, оснащенного фотоумножителем ФЭУ-79, работающим в режиме счета фотонов.
$\mathrm{B}$ спектре поглощения композитных частиц $m \mathrm{SiO}_{2} / \mathrm{CD}$ (рис. 1, кривая 1) наблюдается полоса с максимумом на длине волны $519 \mathrm{~nm}$ с шириной на полувысоте $(\mathrm{FWHM}) \sim 69 \mathrm{~nm}$, обусловленная поглощением излучения фрагментами полиароматических ксантеновых групп прекурсора R6G, встроенных в графеновые слои, формирующие наноточки [14]. В спектре композитных частиц $m \mathrm{SiO}_{2} / \mathrm{Au} / \mathrm{CD}$ (рис. 1 , кривая 2) полоса в данной спектральной области шире (FWHM $\sim 77 \mathrm{~nm}$ ), имеет бо́льшую интенсивность (в 1.7 раза) и ее максимум смещен в длинноволновую область $\left(\lambda_{\max } \sim 524 \mathrm{~nm}\right)$, что обусловлено поглощением ксантеновых фрагментов CD и плазмонной полосой поглощения AuNP [15]. Присутствующее в спектрах обоих типов композитных частиц поглощение в области $300-450 \mathrm{~nm}$, по-видимому, обусловлено поглощением CD $[13,14]$ и $\mathrm{AuNP}$ [15]. Для сравнения на рисунке приведен спектр незаполненных частиц $m \mathrm{SiO}_{2}$ диаметром $450 \mathrm{~nm}$ (кривая 3), в котором наблюдаемое бесструктурное поглощение света мало.

В спектрах ФЛ (рис. 2) суспензий с одинаковой объемной концентрацией $(0.05$ vol.\%) композитных ча-
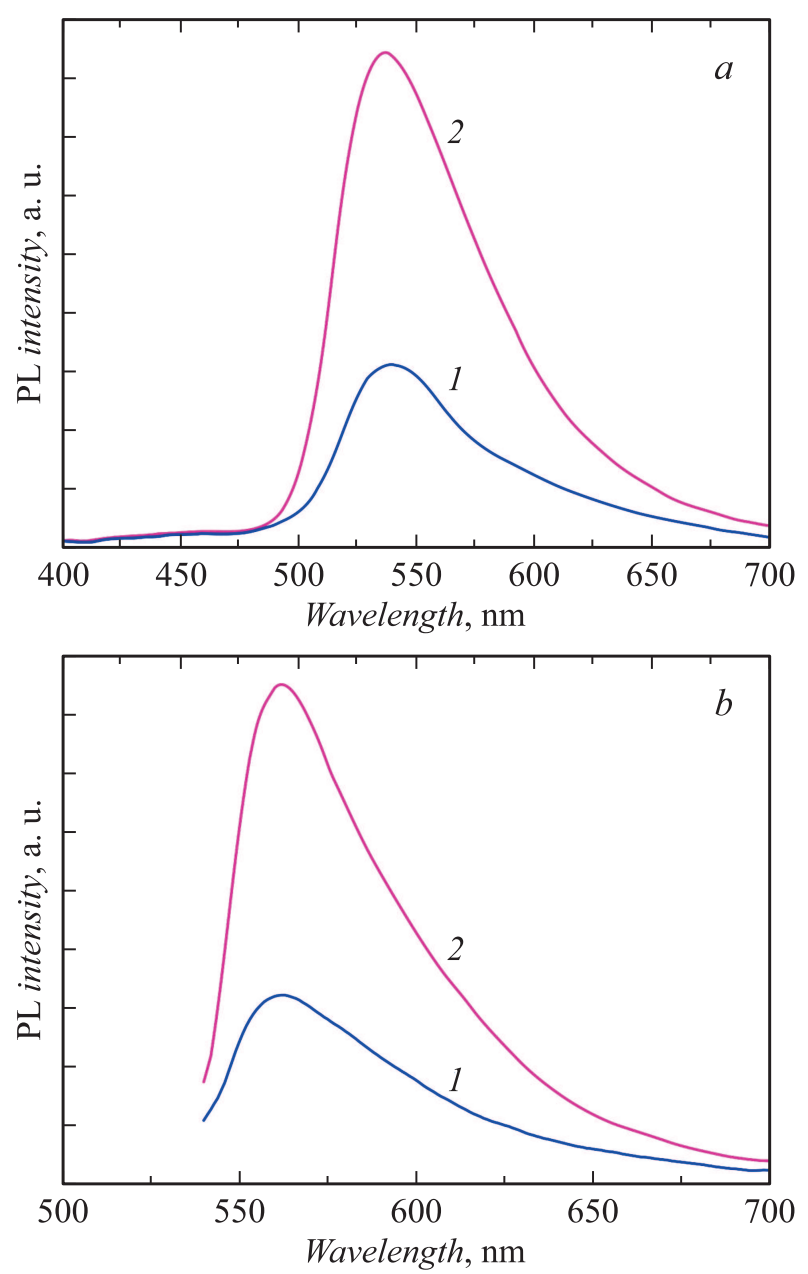

Рис. 2. Спектры фотолюминесценции ( $\lambda_{e x}, \mathrm{~nm}: a-325$, $b-532)$ композитных частиц $m \mathrm{SiO}_{2} / \mathrm{CD}$ (1) и $m \mathrm{SiO}_{2} / \mathrm{Au} / \mathrm{CD}(2)$. 
стиц $m \mathrm{SiO}_{2} / \mathrm{CD}$ и $m \mathrm{SiO}_{2} / \mathrm{Au} / \mathrm{CD}$, содержащих одинаковое (2 vol.\%) количество углеродных наноточек, наблюдаются полосы, обусловленные излучением $\mathrm{CD}$, синтезированных из R6G [15]. Положения максимумов и формы полос ФЛ композитных частиц, имеющих и не имеющих в своем составе AuNP, близки при одинаковом возбуждении. В то же время при возбуждении излучением с разной длиной волны (325 и $532 \mathrm{~nm}$ ) положения максимумов полос ФЛ $\mathrm{CD}$ различаются и составляют 538 и $562 \mathrm{~nm}$ соответственно. Наблюдаемый сдвиг максимума полосы ФЛ в длинноволновую сторону при увеличении длины волны возбуждающего излучения является характерным для углеродных наноточек [16]. При обеих длинах волн возбуждения интенсивность ФЛ частиц, содержащих плазмонные наноструктуры AuNP/CD, приблизительно в 2.8 раза выше, чем интенсивность излучения композитных частиц без золота.

Таким образом, в работе темплатным методом синтезированы обладающие яркой фотолюминесценцией в видимой спектральной области плазмонные структуры, состоящие из углеродных наноточек и наночастиц золота. В качестве темплата использованы монодисперсные сферические мезопористые частицы кремнезема. В качестве прекурсора для синтеза CD выбран Родамин 6Ж, поскольку при его термодеструкции полиароматические фрагменты, которые люминесцируют в области плазмонной полосы поглощения AuNP, встраиваются в графеновые слои углеродных наноточек с сохранением своих свойств. Композитные частицы $m \mathrm{SiO}_{2} / \mathrm{Au} / \mathrm{CD}$ легко расворяются в воде и образуют агрегативно стабильную суспензию. Частицы $m \mathrm{SiO}_{2} / \mathrm{Au} / \mathrm{CD}$ обладают большими значениями удельной поверхности и объема пор $\left(420 \mathrm{~m}^{2} / \mathrm{g}\right.$ и $0.3 \mathrm{~cm}^{3} / \mathrm{g}$ соответственно). Продемонстрировано трехкратное усиление интенсивности флуоресценции частиц $m \mathrm{SiO}_{2} / \mathrm{Au} / \mathrm{CD}$ по сравнению с таковой для частиц, не содержащих золота.

\section{Благодарности}

Авторы выражают благодарность Л.В. Шароновой за измерение спектров поглощения синтезированных частиц.

\section{Финансирование работы}

Работа выполнена при финансовой поддержке Российского фонда фундаментальных исследований (проект № 18-29-19122 мк).

\section{Конфликт интересов}

Авторы заявляют, что у них нет конфликта интересов.

\section{Список литературы}

[1] Baker S.N., Baker G.A. // Angew. Chem. Int. Ed. 2010. V. 49. P. 6726-6744.

[2] Kargbo O., Jin Y., Ding S.-Y. // Current Anal. Chem. 2015. V. 11. P. 4-21.

[3] Yan F., Sun Z., Zhang H., Sun X., Jiang Y., Bai Z. // Microchim. Acta. 2019. V. 186. P. 583.

[4] Kochuveedu S.T., Kim D.H. // Nanoscale. 2014. V. 6. P. 4966 4984.

[5] Zhang Y., Goncalves H., da Silva J.C.G.E., Geddes C.D. // Chem. Commun. 2011. V. 47. P. 5313-5315.

[6] Liu Y., Liu C., Zhang Z., Yang W., Nie S. // J. Mater. Chem. C. 2015. V. 3. P. 2881-2885.

[7] He Q., Shi J. // Adv. Mater. 2014. V. 26. P. 391-411.

[8] Shi Y., Miller M.L., Di Pasqua A.J. // Comments Inorg. Chem. 2016. V. 36. P. 61-80.

[9] Eurov D.A., Kurdyukov D.A., Kirilenko D.A., Kukushkina J.A., Nashchekin A.V., Smirnov A.N., Golubev V.G. // J. Nanopart. Res. 2015. V. 17. P. 82.

[10] Ong C., Cha B.G., Kim J. // ACS Appl. Bio Mater. 2019. V. 2. P. 3630-3638.

[11] Zheng F., Zhang P., Xi Y., Chen J., Li L., Zhu J.-J. // Anal. Chem. 2015. V. 87. P. 11739-11745.

[12] Kurdyukov D.A., Eurov D.A., Kirilenko D.A., Kukushkina J.A., Sokolov V.V., Yagovkina M.A., Golubev V.G. // Microporous Mesoporous Mater. 2016. V. 223. P. 225-229.

[13] Курдюков Д.А., Еуров Д.А., Стовпяга Е.Ю., Кириленко Д.А., Коняхин С.В., Швидченко А.В., Голубев В.Г. // ФTТ. 2016. Т. 58. В. 12. С. 2454-2458.

[14] Еуров Д.А., Курдюков Д.А., Медведев А.В., Голубев В.Г. // Письма в ЖТФ. 2019. Т. 45. В. 18. С. 37-39.

[15] Amendola V., Pilot R., Fracconi M., Maragò O.M., Iatì M.A. // J. Phys.: Condens. Matter. 2017. V. 29. P. 203002.

[16] Nelson D.K., Razbirin B.S., Starukhin A.N., Eurov D.A., Kurdyukov D.A., Stovpiaga E.Y., Golubev V.G. // Opt. Mater. 2016. V. 59. P. $28-33$. 